Carmit Avnon Zivi, ${ }^{a}$, Shimrit Tzvi-Behra, Efrat Ben-Shalom, Choni Rinat, Rachel Becker-Cohen, Floris Levy-Khademi, Jenny Goichberg, Harry J. Hirsch and Yaacov Frishberg

\title{
Early puberty in end stage renal failure and renal transplant recipients
}

https://doi.org/10.1515/jpem-2019-0050

Received January 24, 2019; accepted April 13, 2019; previously published online May 29, 2019

\section{Abstract}

Background: Delayed puberty and hypogonadism are common in children with chronic kidney disease and in renal transplant recipients, but precocious puberty has rarely been reported in these populations. We describe six girls with precocious and/or early-onset, rapidly progressive puberty before and following renal transplantation.

Methods: Of 112 children under the age of 18 years (67 boys, 45 girls) who received renal transplants between 2010 and 2018, six girls presented with precocious or rapidly progressive early puberty at ages $6-7 / 12,7-2 / 12$, $7-4 / 12,8,8-8 / 12$ and $8-11 / 12$ years. Clinical evaluation included measurements of height, weight, body mass index (BMI), Tanner staging and bone age assessment. Gonadotropin responses to intravenous gonadotropin releasing hormone $(\mathrm{GnRH})$ or intramuscular triptorelin acetate were determined.

Results: Tanner breast stage 3 was noted at 2-6 years following renal transplantation in five girls, four with preserved kidney function. One girl began puberty before renal transplantation. Peak luteinizing hormone (LH) and follicular stimulating hormone (FSH) levels were 6.5, 20.2, 7.83, 19.1, 9 and $2.2 \mathrm{mIU} / \mathrm{mL}$ and 13, 8.3, 8.01, 7.5, 8.1 and $7.7 \mathrm{mIU} / \mathrm{mL}$, respectively. Treatment with an intramuscular slow-release formulation of triptorelin acetate every 4 weeks slowed progression of breast development.

${ }^{a}$ Carmit Avnon Ziv and Shimrit Tzvi-Behr are equally contributed to this work.

*Corresponding author: Dr. Carmit Avnon Ziv, MD, Pediatric Endocrinology Unit, Department of Pediatrics, Shaare Zedek Medical Center, P.O. Box 3235, Jerusalem 91031, Israel, Phone: +972-508573125, Fax: +972-2-6555750,

E-mail: zcarmit@szmc.org.il. https://orcid.org/0000-0001-8236-1974

Shimrit Tzvi-Behr, Efrat Ben-Shalom, Choni Rinat, Rachel Becker-

Cohen, Jenny Goichberg and Yaacov Frishberg: Division of Pediatric Nephrology, Shaare Zedek Medical Center, Jerusalem, Israel Floris Levy-Khademi and Harry J. Hirsch: Pediatric Endocrinology Unit, Department of Pediatrics, Shaare Zedek Medical Center, Jerusalem, Israel
Conclusions: Although delayed puberty is more common in children with renal disease, precocious puberty can also be seen. Evaluation of growth and puberty by a pediatric endocrinologist should be part of the routine care for all children following kidney transplantation.

Keywords: chronic kidney disease; early puberty; precocious puberty; premature thelarche; puberty in chronic diseases; renal transplantation.

\section{Introduction}

Growth retardation and delayed puberty are common in children with chronic illnesses including chronic kidney disease (CKD). Depending on the severity and duration of the renal disease, onset of puberty has often been delayed by $2-2.5$ years in both sexes [1]. The rate of pubertal progression is usually slow compared to that of normal children and the magnitude of height gain during puberty is diminished [1]. Poor nutrition, chronic inflammation, acid-base and electrolyte abnormalities associated with uremia, and at times, chronic glucocorticoid treatment may interfere with normal pubertal development in these children [2]. With newer approaches to the treatment of children with CKD, such as earlier renal transplantation, puberty often progresses at a normal tempo, even when the onset of puberty is delayed [3].

Precocious puberty is defined as thelarche starting before the age of 8 in girls with progression of breast development and in most cases accelerated growth. The mean age of puberty worldwide appears to be declining [4].

We describe six girls from our pediatric nephrology service who developed precocious or early-onset, rapidly progressive puberty before and following renal transplantation.

\section{Study participants and methods}

Children with chronic kidney disease including those who underwent kidney transplantation followed in the 
pediatric nephrology unit at the Shaare Zedek Medical Center, Jerusalem, are routinely seen by a pediatric endocrinologist for assessment of growth and pubertal development. Between January 2010 and July 2018, 112 children (67 boys, 45 girls) aged 2-18 years who were recipients of a kidney transplantation, were actively followed.

During this period, we observed six girls (ages 6-7/12, $8,7-2 / 12,8-8 / 12,7-4 / 12$ and $8-11 / 12$ years) with precocious or rapidly progressive early puberty either before or following living related-donor or deceased-donor kidney transplantation due to end stage kidney disease because of various etiologies as depicted in Table 1. Clinical evaluation included measurements of height, weight, body mass index (BMI) and Tanner staging of puberty [5] by one of two endocrinologists in our center. Bone age was determined according to the method of Greulich and Pyle [5]. Serum hormone measurements were performed using standard chemiluminescence assays [6, 7]. Gonadotropin levels were measured immediately before and at 20, 40, and $60 \mathrm{~min}$ after intravenous gonadotropinreleasing hormone $100 \mu \mathrm{g}$ (GnRH, Ferring GmbH, Kiel, Germany) or $1 \mathrm{~h}$ following the first intramuscular (i.m.) dose $(3.75 \mathrm{mg}$ ) of the depot $\mathrm{GnRH}$ agonist, triptorelin acetate (Decapeptyl CR, Ferring GmbH, Kiel, Germany). An increase in luteinizing hormone (LH) to over $5 \mathrm{IU} / \mathrm{L}$, or 3 times baseline LH levels, and baseline estradiol greater than $37 \mathrm{pmol} / \mathrm{L}$ are considered to be consistent with central precocious puberty $[8,9]$.

The study was approved by the Helsinki committee of the Shaare Zedek Medical Center.

\section{Results}

\section{Case \#1}

A Muslim Arab girl, with end stage kidney disease due to familial juvenile nephronophthisis underwent pre-emptive living-related donor kidney transplantation at age $6-8 / 12$ years. On examination a month before transplantation breast development was Tanner stage 2 and pubic hair was Tanner stage 2. Her medications at the diagnosis of premature puberty included epoetin beta, polyethylene glycol, amlodipine, alfacalcidol, sodium bicarbonate, calcium carbonate, iron and recombinant human growth hormone. Her serum creatinine was $4.9 \mathrm{mg} / \mathrm{dL}$ with an estimated glomerular filtration rate (eGFR) of $9 \mathrm{~mL} / \mathrm{min} / 1.73 \mathrm{~m}^{2}$. Before renal transplantation - LH was undetectable at baseline and 2.2 IU/L after stimulation, estradiol level was $92 \mathrm{pmol} / \mathrm{L}$ which was elevated for her age. Bone age was delayed (Table 2). Mid-parental height was $168 \mathrm{~cm}$, and predicted height was $160 \mathrm{~cm}$. On abdominal ultrasound the right ovary measured $0.8 \times 1.1 \mathrm{~cm}$, the left ovary was $0.8 \times 1.1 \mathrm{~cm}$, with a follicle of $0.8 \mathrm{~cm}$ and the uterus was $1.5 \times 0.8 \mathrm{~cm}$. Brain magnetic resonance imaging (MRI) was normal. Androgen levels were not elevated. Thyroid function tests were normal. Kidney transplantation was successful and serum creatinine level dropped to $0.4 \mathrm{mg} / \mathrm{dL}$ with an eGFR of $115 \mathrm{~mL} / \mathrm{min} / 1.73 \mathrm{~m}^{2}$. Medications following kidney transplantation included prednisone, tacrolimus, mycophenolic acid, ranitidine, valganciclovir, co-trimazole, aspirin, magnesium citrate, iron and calcium carbonate.

Table 1: Nephrologic characteristics of patients.

\begin{tabular}{|c|c|c|c|c|}
\hline Patient & Primary diagnosis & $\begin{array}{l}\text { Duration of dialysis } \\
\text { before kidney } \\
\text { transplantation, years }\end{array}$ & $\begin{array}{r}\text { Age at } \\
\text { transplantation, } \\
\text { years }\end{array}$ & $\begin{array}{r}\text { eGFR at the time of early } \\
\text { puberty diagnosis, } \\
\mathrm{mL} / \mathrm{min} / 1.73 \mathrm{~m}^{2}\end{array}$ \\
\hline 1 & $\begin{array}{l}\text { Juvenile } \\
\text { nephronophthisis }\end{array}$ & $\begin{array}{l}\text { None - preemptive } \\
\text { renal transplantation }\end{array}$ & $6-8 / 12$ & 9 \\
\hline 2 & $\begin{array}{l}\text { Primary hyperoxaluria } \\
\text { type } 1\end{array}$ & $1-6 / 12$ & 2 & 74 \\
\hline 3 & $\begin{array}{l}\text { Finnish type congenital } \\
\text { nephrotic syndrome }\end{array}$ & $1-2 / 12$ & $3-9 / 12$ & 85 \\
\hline 4 & $\begin{array}{l}\text { Single dysplastic } \\
\text { kidney }\end{array}$ & $1-6 / 12$ & $6-6 / 12$ & 66 \\
\hline 5 & Polycystic kidneys & $\begin{array}{l}\text { None - preemptive } \\
\text { renal transplantation }\end{array}$ & 5 & 83 \\
\hline 6 & $\begin{array}{l}\text { Focal segmental } \\
\text { glomerular sclerosis }\end{array}$ & $1-7 / 12$ & $7-5 / 12$ & 46 \\
\hline
\end{tabular}

eGFR (estimated glomerular filtration rate)-based on the bedside Schwartz formula for glomerular filtration rate. 


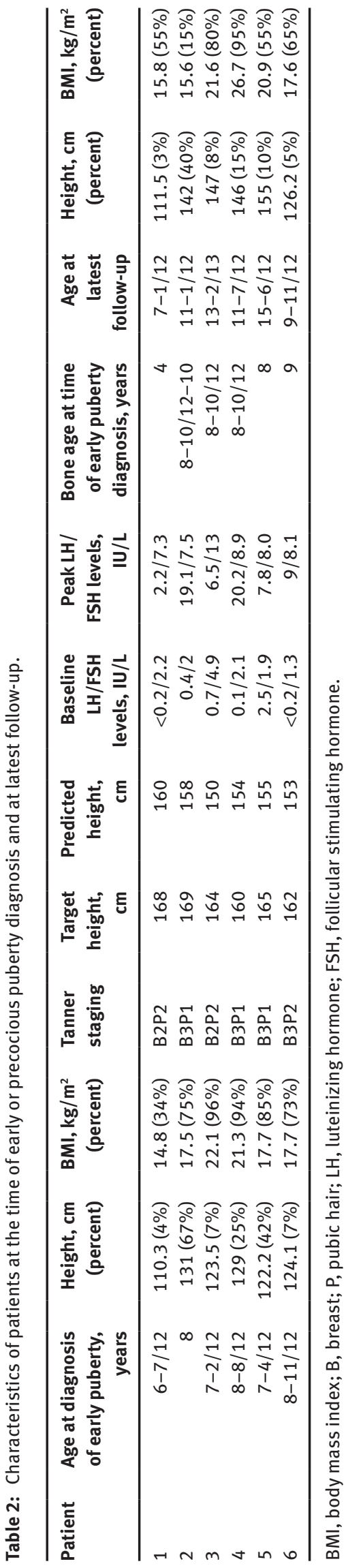

Two months after her renal transplantation thelarche progressed rapidly to Tanner stage 3 as examined by the same physician. Baseline LH rose to $1 \mathrm{IU} / \mathrm{L}$. Because of clinical progression in puberty and a rise in baseline LH at the age of 6-10/12 treatment with triptorelin acetate every 28 days was started. She continues to receive $\mathrm{GnRH}$-agonist treatment, with regression of breast tissue. Gonadotropins and estradiol are suppressed with treatment.

\section{Case \#2}

A Muslim Arab girl, with primary hyperoxaluria type 1 treated with chronic hemodialysis since the age of 5 months, underwent a combined deceased-donor liver and kidney transplantation at the age of 2 years. She was referred for endocrine evaluation at the age of 8 years because of early and rapidly progressive thelarche (Tanner stage 3). On abdominal ultrasound the right ovary measured $2.5 \times 1.6 \mathrm{~cm}$, the left ovary measured $2.2 \times 1.3 \mathrm{~cm}$, the uterus was $2.5 \times 1.6 \mathrm{~cm}$ and the uterine mucosal thickness was $2.4 \mathrm{~mm}$. Medications included prednisone ( $3 \mathrm{mg}$ every second day), tacrolimus, mycophenolic acid, potassium and sodium citrate, calcium carbonate and vitamin D. Her serum creatinine level was $0.73 \mathrm{mg} / \mathrm{dL}$ with an eGFR of $74 \mathrm{~mL} / \mathrm{min} / 1.73 \mathrm{~m}^{2}$. Thyroid function tests were normal. Gonadotropin levels were elevated, and the bone age was advanced (Table 2), consistent with early puberty. Mid-parental height was $169 \mathrm{~cm}$, and predicted height was $158 \mathrm{~cm}$. Treatment with triptorelin acetate once every 28 days was initiated at age 8-4/12 years. During treatment, gonadotropin levels and estradiol were suppressed, with no advancement of thelarche, but pubarche advanced slowly to Tanner stage 3. GnRH treatment was discontinued at the age of 10 years. At the age of 11 years she has not yet had menarche.

\section{Case \#3}

A Muslim Arab girl, with Finnish type congenital nephrotic syndrome, underwent deceased-donor kidney transplant at age 3-9/12 years. Hypothyroidism associated with congenital nephrotic syndrome was diagnosed shortly after birth and supplemental l-thyroxine therapy was initiated. Breast development was first noted at age 7-2/12 years with Tanner breast stage 2 and Tanner pubic hair stage 1 . She was diagnosed with mild early thelarche. At the age of 8-4/12 early rapidly progressing puberty was diagnosed with breast development at Tanner stage 2 and pubic hair 
at Tanner stage 2. Mid-parental height was $164 \mathrm{~cm}$, and predicted height was $150 \mathrm{~cm}$. Because her final height was predicted to be short due to rapidly progressive puberty and advanced bone age, treatment with the GnRH agonist triptorelin acetate once every 28 days was recommended. Due to problems in obtaining insurance coverage, treatment was not actually begun until age 9-4/12. Thyroid function tests were normal on a l-thyroxine dose of $50 \mu \mathrm{g} 5$ times weekly. Additional medications included prednisone (3.6 mg every second day), mycophenolate mofetil, and tacrolimus. Her serum creatinine level at the onset of thelarche was $0.6 \mathrm{mg} / \mathrm{dL}$ with an eGFR of $85 \mathrm{~mL} /$ $\mathrm{min} / 1.73 \mathrm{~m}^{2}$ and remained so until the age of 12 years. During the treatment period gonadotropins and estradiol levels were suppressed and there was no clinical progression of breast development. GnRH treatment was discontinued at the age of 11-10/12 years. Menarche occurred at the age of $12-4 / 12$ years.

\section{Case \#4}

A Muslim Arab girl, with a single dysplastic kidney underwent deceased-donor kidney transplantation at the age of $6-6 / 12$ years. On examination at age $8-8 / 12$ years breast development was at Tanner stage 3 and pubic hair was at Tanner stage 1. Medications included prednisone (5 mg on alternate days), tacrolimus, mycophenolic acid and calcitriol. Serum creatinine was $0.8 \mathrm{mg} / \mathrm{dL}$ with an eGFR of $66 \mathrm{~mL} / \mathrm{min} / 1.73 \mathrm{~m}^{2}$. Thyroid function tests were normal. On abdominal ultrasound the right ovary measured $2 \times 1.1 \times 1.9 \mathrm{~cm}$ and the left ovary $3.3 \times 1.5 \times 2.4 \mathrm{~cm}$ with small follicles bilaterally. Hormone levels and bone age (Table 2) indicated rapidly progressive early puberty. Mid-parental height was $160 \mathrm{~cm}$, and predicted height was $154 \mathrm{~cm}$. She was treated with triptorelin acetate once every 28 days from age 9-4/12 until the age of 11-1/12 years. During the treatment period gonadotropins and estradiol levels were suppressed and there was no clinical progression of breast development. Menarche occurred at the age of $12-5 / 12$ years.

\section{Case \#5}

An Ashkenazi Jewish girl developed CKD due to autosomal recessive polycystic kidney disease and underwent preemptive living-related donor kidney transplantation at the age of 5 years. On examination at age $7-4 / 12$ years she had Tanner stage 3 breast development, while pubic hair was at Tanner stage 1. On abdominal ultrasound the right ovary measured $1.3 \times 1.8 \mathrm{~cm}$, the left ovary was $1.9 \times 1.3 \mathrm{~cm}$, and the uterus was $2.2 \times 1 \mathrm{~cm}$. Medications included prednisone (5 mg on alternate days), tacrolimus, mycophenolic acid, calcium carbonate, vitamin D, aspirin and iron supplement. Her serum creatinine was $0.6 \mathrm{mg} / \mathrm{dL}$ and the eGFR was $83 \mathrm{~mL} / \mathrm{min} / 1.73 \mathrm{~m}^{2}$. Thyroid function tests were normal. Hormone levels and bone age (Table 2) indicated central precocious puberty. Mid-parental height was $165 \mathrm{~cm}$, and predicted height was $155 \mathrm{~cm}$. Treatment with triptorelin acetate from age 8-2/12 years until age 11 years resulted in prepubertal levels of gonadotropins and estradiol and no further advancement in Tanner breast stage. Menarche occurred at the age of $12-8 / 12$ years.

\section{Case \#6}

A Muslim Arab girl presented at the age of 2-10/12 years with steroid resistant nephrotic syndrome. Solumedrol pulses and cyclosporine treatments were unsuccessful and she gradually progressed to end stage renal disease. Although her kidney biopsy was consistent with minimal change NS, focal segmental glomerulosclerosis (FSGS) could not be excluded. Chronic dialysis was started at the age of $5-10 / 12$ years. She underwent living-related kidney transplantation at age 6-8/12 years. Shortly afterwards there was a recurrence of the FSGS in the transplanted kidney and she started chronic plasmapheresis treatments. At the age of 8-11/12 years, rapidly progressing early puberty was noted, though growth was stunted. Tanner breast stage advanced from 1 to 3 within 2 months. Her serum creatinine was $1.1 \mathrm{mg} / \mathrm{dL}$ with an eGFR of $46 \mathrm{~mL} / \mathrm{min} / 1.73 \mathrm{~m}^{2}$. Hormone levels (Table 2), indicated early puberty. Mid-parental height was $162 \mathrm{~cm}$, and predicted height was $153 \mathrm{~cm}$. On abdominal ultrasound the right ovary measured $3.3 \times 0.6 \times 2.1 \mathrm{~cm}$, the left ovary was $2.5 \times 1.3 \times 1.9 \mathrm{~cm}$ with many small follicles and the uterus showed an endometrium of $0.3 \mathrm{~cm}$. Androgen levels were not elevated. Thyroid function tests were normal. Medications included prednisone (5 mg on alternate days), tacrolimus, mycophenolic acid, iron, amlodipine, sodium bicarbonate, vitamin $\mathrm{D}$, metoprolol, doxazosin mesylate, losartan-potassium, darbepoetin alfa and calcium carbonate. In addition, her plasmapheresis protocol included fresh frozen plasma, albumin and supplemental intravenous human immunoglobulin therapy.

Treatment with triptorelin acetate every 28 days was started at the age of 9-7/12 years because of rapidly progressing puberty with growth retardation. Growth 
hormone treatment was started at this time as well at $0.045 \mathrm{mg} / \mathrm{kg} /$ day. She continues to receive GnRH-agonist treatment.

\section{Discussion}

The onset of puberty in girls occurs normally between the ages of 8 and 13. The most common mechanism of precocious puberty is the early activation of pulsatile $\mathrm{GnRH}$ secretion and is usually idiopathic in girls. Pathological etiologies include brain lesions, endocrine disrupters, genetic changes such as gain-of-function mutations in the genes encoding kisspeptin (KISS1) and kisspeptin receptor (KISS1R), and loss-of-function mutations in makorin ring finger 3 (MKRN3) [10]. Adiposity itself may contribute to the early onset of puberty - higher levels of leptin and kisspeptin expression are modulators between nutrition and the timing of puberty [11].

Delayed puberty and growth retardation are common in children with chronic diseases, including CKD. Contributing factors include malnutrition, inflammation, acidbase and electrolyte abnormalities associated with uremia [2]. There are few case reports of boys with renal failure and precocious puberty $[12,13]$. Improved nutrition and early kidney transplantation improve growth and result in normal or near-normal onset and progression of puberty $[14,15]$. Recently Winter et al. in a report of precocious puberty in children with chronic disease described one boy with renal failure and precocious puberty [16].

Overnight secretion of growth hormone and gonadotropins is blunted in children receiving long term glucocorticoids which are often prescribed for treatment of steroid-dependent nephrotic syndrome or to prevent renal transplant rejection [17]. Hypofunction of the GnRH pulse generator was observed in children with end-stage renal disease, irrespective of glucocorticoid treatment. Animal studies suggest that this may be due to uremia-related inhibitory factors or an increase in the hypothalamus of the inhibitory neurotransmitter gamma-aminobutyric acid [3]. Despite decreased secretion of LH from the pituitary gland, serum concentrations of LH may be elevated due to impaired renal clearance, but bioactivity of LH is decreased in uremic patients. Plasma estradiol levels in women tend to decrease in parallel with GFR reduction [3]. Ghanem et al. showed that male and female renal transplant recipients generally have significant delays in onset of puberty, and girls have delayed menarche compared to healthy controls, especially if the duration of uremia was longer and the age at transplantation was older [18].
Recent improvements in the medical management of uremic patients may achieve normal pubertal onset and progression in these children. The likelihood of normal pubertal development is greater for those children who undergo transplantation at a young age. Tainio et al. found, in a retrospective study of 109 children, that those who underwent renal transplantation before the age of 5 years reached puberty earlier than did children who were older at the time of transplantation. Early puberty was observed in 2/29 girls and 1/55 boys [15]. Menarche occurred at an older age in the overweight girls compared to those with normal BMI values. There was no difference in the timing of puberty between obese and non-obese boys. The authors noted that their patient population differs from other populations, in that most have Finnish type congenital nephrotic syndrome and underwent transplantation at a very young age, without exposure to prolonged periods of uremia [15].

Forster and colleagues showed that if long-term dialysis is avoided, renal transplantation appears to normalize GnRH pulsatile secretion [14]. Almost all of their posttransplant patients, ages 16-16-9/12 years had normal levels of LH, follicular stimulating hormone (FSH) and estradiol. The median age for menarche in this study was $12-7 / 12$ years, 3/27 girls had early menarche (as compared with an age-matched population) at the age of less than 10-7/12 years. Only one girl had delayed menarche ( $>15$ years) [14].

In the past 30 years, children with CKD attain taller final heights and puberty begins at a younger age than in older cohorts. Acidosis, anemia and poor nutrition were factors that contributed to the delay in growth and puberty [19]. When these factors are controlled by conservative management, causes of delayed puberty, other than renal failure need to be considered, including syndromes such as gonadal dysgenesis, WT1 mutations, or medical treatments that interfere with pubertal development, such as glucocorticoid treatment [3].

In healthy children, the onset of puberty is earlier in obese girls, although menarche is not [20]. Endocrine disrupters are also known factors to influence puberty [21]. There is no evidence of abnormal exposure to such factors in our patients.

Ardissino et al. followed approximately 1500 children with renal failure and assessed the decline in eGFR during pubertal growth spurt in 40 of them. Kidney function declined more rapidly during puberty than before puberty. They found that this decline occurs earlier in females than in males. The contributing factors to this decline, such as sex hormones or maladaptation of the kidney to rapid growth are still unknown [22]. 
The youngest of our patients (\#1) began puberty even though she had compromised kidney function. She has nephronophthisis, a condition that is accompanied by growth retardation as a manifestation of chronic kidney disease [23]. This, or the early detection of her advancing puberty may explain her delayed bone age. Another girl (\#6) experienced very rapidly progressing early puberty even though she had recurrence of her primary kidney disease (FSGS) following kidney transplantation which was complicated by kidney failure and accompanied by linear growth retardation, while being treated with plasmapheresis for her kidney disease.

We describe six girls, who presented with premature or early thelarche before or following kidney transplantation. All six girls showed pubertal levels of gonadotropins or estradiol following GnRH or triptorelin stimulation tests. Three of the six had advanced bone age. Two girls are slightly overweight, and the other three are obese. There are controversies in the literature about GnRH treatment in premature and early thelarche - who to treat, at what age and when to stop treatment. Although the efficacy of GnRH agonist treatment for borderline, early puberty is questionable, [4] we nevertheless chose to treat our patients in view of the rapid rates of pubertal progression, the increased risk for deterioration of renal function and anticipated short final heights.

As in the general population, obesity may be a contributing factor to earlier onset of puberty in girls following renal transplantation, especially in those with preserved renal function. Further studies are needed to examine the interaction of obesity with the hypothalamicpituitary-gonadal axis in boys and girls with CKD and following renal transplantation. Evaluation of growth and puberty by a pediatric endocrinologist should be considered part of the routine care of all children with chronic kidney disease including renal transplant recipients as premature puberty is amenable to therapy.

Acknowledgments: The authors would like to acknowledge the nursing staff at our center for their dedicated care of our patients.

Author contributions: All the authors have accepted responsibility for the entire content of this submitted manuscript and approved submission.

Research funding: None declared.

Employment or leadership: None declared.

Honorarium: None declared.

Competing interests: The funding organization(s) played no role in the study design; in the collection, analysis, and interpretation of data; in the writing of the report; or in the decision to submit the report for publication.

\section{References}

1. Schaefer F, Seidel C, Binding A, Gasser T, Largo RH, et al. Pubertal growth in chronic renal failure. Pediatr Res 1990;28:5-10.

2. Simon D. Puberty in chronically diseased patients. Horm Res 2002;57(Suppl 2):53-6.

3. Haffner D, Zivicnjak M. Pubertal development in children with chronic kidney disease. Pediatr Nephrol 2017;32:949-64.

4. Kaplowitz PB, Backeljauw PF, Allen DB. Toward more targeted and cost-effective gonadotropin-releasing hormone analog treatment in girls with central precocious puberty. Horm Res Paediatr 2018;90:1-7.

5. Greulich WW, Pyle SI. Radiographic atlas of skeletal development of the hand and wrist. Second ed. Stanford, CA: Stanford University Press; 1959.

6. Abbott Company Website [Internet]. Available from: https:// www.corelaboratory.abbott/us/en/offerings/brands/architect/ architect-i1000SR [cited 2017 Nov 4].

7. Seimens Healthineers [Internet]. Available from: https:// www.healthcare.siemens.com/immunoassay/systems [cited 2017 Nov 4].

8. Sathasivam A, Garibaldi L, Shapiro S, Godbold J, Rapaport R. Leuprolide stimulation testing for the evaluation of early female sexual maturation. Clin Endocrinol (Oxf) 2010;73:375-81.

9. Blondell RD, Foster MB, Dave KC. Disorders of puberty. Am Fam Physician 1999;60:223.

10. Latronico AC, Brito VN, Carel J-C. Causes, diagnosis, and treatment of central precocious puberty. Lancet Diabet Endocrinol 2016;4:265-74.

11. Shalitin S, Kiess W. Putative effects of obesity on linear growth and puberty. Horm Res Paediatr 2017;88:101-10.

12. Loh KC, Salisbury SR, Accott P, Gillis R, Crocker JF. Central precocious puberty and chronic renal failure: a reversible condition post renal transplantation. J Pediatr Endocrinol Metab 1997;10:539-45.

13. Geffner ME, Kaplan SA, Lippe BM, Fine RN. Precocious puberty and chronic renal failure. Am J Dis Child 1983;137:956-8.

14. Förster J, Ahlenstiel-Grunow T, Zapf A, Mynarek M, Pape L. Pubertal development in pediatric kidney transplant patients receiving mammalian target of rapamycin inhibitors or conventional immunosuppression. Transplantation 2016;100:2461-70.

15. Tainio J, Qvist E, Vehmas R, Jahnukainen K, Hölttä T, et al. Pubertal development is normal in adolescents after renal transplantation in childhood. Transplantation 2011;92: 404-9.

16. Winter S, Durand A, Brauner R. Precocious and early central puberty in children with pre-existing medical conditions: a single center study. Front Pediatr 2019;7:35.

17. Rees L, Greene SA, Adlard P, Jones J, Haycock GB, et al. Growth and endocrine function after renal transplantation. Arch Dis Child 1988;63:1326-32.

18. Ghanem ME, Emam ME, Albaghdady LA, Bakr NI, Helal AS, et al. Effect of childhood kidney transplantation on puberty. Fertil Steril 2010;94:2248-52.

19. Franke D, Winkel S, Gellermann J, Querfeld U, Pape L, et al. Growth and maturation improvement in children on renal replacement therapy over the past 20 years. Pediatr Nephrol 2013;28:2043-51. 
20. Ahmed ML, Ong KK, Dunger DB. Childhood obesity and the timing of puberty. Trends Endocrinol Metab 2009;20:237-42.

21. Greenspan LC, Lee MM. Endocrine disrupters and pubertal timing. Curr Opin Endocrinol Diabet Obes 2018;25:49-54.

22. Ardissino G, Testa S, Daccò V, Paglialonga F, Viganò S, et al. Puberty is associated with increased deterioration of renal function in patients with CKD: data from the ItalKid Project. Arch Dis Child 2012;97:885-8.
23. Stokman M, Lilien M, Knoers N. Nephronophthisis. In: Adam MP, Ardinger HH, Pagon RA, Wallace SE, Bean LJ, et al., editors. GeneReviews $^{\circledR}$. Seattle (WA): University of Washington, 1993.

Article note: The datasets generated during and/or analyzed during the current study are available from the corresponding author on reasonable request. 